\title{
TOWARD A POLITICAL THEORY OF SOCIAL INNOVATION: COLLECTIVE INTELLIGENCE AND THE CO-CREATION OF SOCIAL GOODS
}

\author{
MICHAEL A. PETERS \\ mpeters@waikato.ac.nz \\ University of Waikato; \\ University of Illinois at Urbana-Champaign \\ RICHARD HERAUD \\ University of Waikato
}

\begin{abstract}
This paper proposes a political theory of social innovation. The paper begins by introducing and reviewing recent claims made for the ways in which social innovation can co-create public goods and services by utilizing forms of collection intelligence (CI) and CI Internet-based platforms. The paper provides a discussion and classification of the literature on collective intelligence before investigation the question of new forms and ways of delivering public goods and services through forms of co-creation and co-production.
\end{abstract}

\section{JEL codes: O31; Q55; L86}

Keywords: social innovation; political theory; collective intelligence; co-creation; public goods

How to cite: Peters, Michael A., and Richard Heraud (2015), "Toward a Political Theory of Social Innovation: Collective Intelligence and the Co-Creation of Social Goods," Journal of Self-Governance and Management Economics 3(3): 7-23.

Received 8 May 2015 • Received in revised form 21 May 2015

Accepted 26 May 2015 • Available online 15 September 2015

\section{Introduction}

The literature on social innovation grew quickly in the early 2000s and is now voluminous. One definition suggests that social innovation can be understood by the "penetration of business ideas, management practices, and market principles into the world of and nonprofits and government" (Phills, 2009). This American-styled view puts the emphasis on social enterprise and social 
entrepreneurship, as is evidenced in the work of the Stanford Center for Social Innovation in the Graduate School of Business. In this context, the underlying concern is the creation of social value by solving social problems, where social innovation exhibits both "novelty" and the idea of "improvement." Phills (2009) states that social innovation refers to:

[a]ny novel and useful solution to a social need or problem, that is better than existing approaches (i.e., more effective, efficient, sustainable, or just) and for which the value created (benefits) accrues primarily to society as a whole rather than private individuals (Phills, 2009)

Social innovation builds on the back of "open innovation," and also has direct application to government and the public sector. Thus, one recent symposium "Innovating Together: Co-creation and Co-production of Public Services"1 defined "open innovation," in the first instance, in terms of harvesting ideas outside the firm before applying these ideas to the public sector:

Open innovation assumes that firms can and should use external ideas as well as internal ideas, and internal and external paths to market, as the firms look to advance their technology. Open innovation, therefore, encourages organizations to search for solutions outside their organizational boundaries. Implementing open innovation in the public sector has a myriad of positive effects, including increased awareness of social problems, more effective practices based on broad citizen experience, and increased trust between government and citizens.

This symposium defines open innovation in the public sector in terms of the active participation of citizens. (I prefer the term "engagement"). The webpage goes on to state:

This involvement is often referred to as co-creation and coproduction. Although these terms were introduced back in the 70s, recently they have gained a renewed interest as a result of technological developments, which have given citizens more control, allowing for new ways of interaction and involvement, particularly in public services delivery.

What began as an economic theory, based on social media principles, has more recently become a political theory of social innovation. This theoretical development has, it would seem, been formed to create citizens capable of participating in collective problem solving through co-creating, co-designing, and co-evaluating social goods and services. In part, this initiative trades on the ethos of collaboration, sharing and interconnectivity at the heart of new social media technologies while also recognizing that complex social problems require the mass collaboration of the many, of engaged citizens, especially in times of austerity. These developments have led commentators to talk of social 
innovation ecosystems and platforms designed to promote a shared public view, to exchange knowledge and to enhance mass participation in problemsolving activities (Nambisan \& Nambisan, 2013). The term "smart cities" is associated with a movement towards greater use of digital technologies, which, while enhancing well being also has the effect of cutting costs through the active participation of citizens (Komininos, 2008).

Christian Bason, the director of the Danish innovation unit MindLab and author of Leading Public Sector Innovation: Co-creating for a Better Society (2010) writes:

In order to make such paradigmatic innovation much more likely, leaders in government must build an infrastructure of innovation a public-sector innovation ecosystem. The ecosystem is built through four simultaneous shifts in how the public sector creates new solutions: a shift from random innovation to a conscious and systematic approach to public sector renewal; a shift from managing human resources to building innovation capacity at all levels of government; a shift from running tasks and projects to orchestrating processes of cocreation, creating new solutions with people, not for them; a shift from administrating public organizations to courageously leading innovation across and beyond the public sector. ${ }^{2}$

The effective creation of such an innovation ecosystem would seem to depend on the extent to which these shifts to create new solutions in the public sector, which we take to include public education, are commensurable with one another; this commensurability at its crux depending on who the concept of innovation is understood. The latter falls on the theoretical problem of whether or not the last three described shifts can be facilitated by the first. An approach that facilitates random innovation may in fact be closer in its understanding of innovation than the systemization of the governance of how innovation is to be achieved - that is unless this systemization is open to random and spontaneous improvements to its own organization. The latter three shifts refer to greater social participation in innovation, greater implication in the problem of innovating and greater opportunities for these parties to extent to scope of the ecosystem. This new participation, implication and extension of interest cannot be framed according to existing notions of cocreation. Working with unforeseen diversity supposes working with new knowledge and knowledge that must resist systemization in order to collaborate with existing technologies of power.

More and more theorists and commentators are focusing on citizens' value-creation processes (Magno \& Cassia, 2014) and reviewing co-creation and co-production as the basis for systematic reform of the public sector. While we see Baston's (2010) formulation of an innovation ecosystem being one that would appear to acknowledge the participation and implication of a 
bottom-up involvement in co-creation and co-production, not all the literature signals that co-production should be understood to imply this type of involvement. For example, Pestoff (2012), while providing a series of definitions of co-production in relation to what he regards as the crucial conceptual issues, includes teachers and direct citizen participation but makes not room for students as co-producers and collaborators of those who might bring about social change. To avoid this aspect of what co-production might mean is to avoid the problem of embracing the idea that the reason why we are not willing to see students as co-producers of social change during the years in which they are studying might be because the preparation of co-produce, as it were, would involve a political education that the state could not entertain.

This brings us to the need to state how we understand social innovation. In this context Vorrberg et al. (2014) define social innovation as

the creation of long-lasting outcomes that aim to address societal needs by fundamentally changing the relationships, positions and rules between the involved stakeholders, through an open process of participation, exchange and collaboration with relevant stakeholders, including endusers, thereby crossing organizational boundaries and jurisdictions (Hartley 2005; Bason 2010; Osborne and Brown 2011; Sorensen and Torfing 2011; Chesbrough 2003, 2006) (p. 2).

The emphasis in this definition is on the process of open participation by citizens changing the "relationships, positions and rules" among "stakeholders." In as much as the above definition of social innovation seems useful, it equally misses the political point with respect to the ways in which new forms of collective behavior, that are enabled by social media, encourage and promote collaborative problem solving.

\section{Collective Intelligence}

Geoff Mulgan (2014) suggests that while there are some stunning examples of collective intelligence in social media, this field of behavior remains largely undeveloped and untheorized. Mulgan locates this field in the space where institutions and systems become more intelligent, and where the organization of machine learning and human behavior interact to produce collective intelligence. He elaborated this concept via an engagement with Verdansky's concept of "noosphere;" the third phase of collective intelligence that comes, historically-speaking, after the development of the "geosphere" and "biosphere." "Noosphere" refers to "an emergent global realm of human thought" (Lévy 2000, as cited in Peters \& Reveley, 2014). Mulgan goes on to provide a series of contemporary examples in a variety of fields such as open software, anthropology, politics and so on, as forms of collective intelligence, which can be 
thought to include "epistemic democracy," concepts of a "global brain," the embodied cognition of the extended mind and the like. He makes a case for a better definition of the concept of collective intelligence and establishes an experimental agenda, referencing the "ecology of tools" that is collectively emerging in sync with the development of platforms on the Internet. Mulgan's (2014) paper is insightful although a little disorganized when it comes to drawing the theoretical connections between the major paradigms that separately contribute to the formation collective intelligence while at the same time proceeding from the same impulse. The issue might be with the fact that his spectrum of problems that this ecology of tools is to be used to address is not broad enough as a set of problems that would suffice for describing our common predicament - that of man, other species and the planet. He identifies "problems of health knowledge," ... "problems of politics," ... "problems of economies," ... and "problems of ecology" (p. 134). What of problems of education? Surely our configuration of what we consider to be a problem is founded in the formation of our capacity to make our thinking collectively intelligible; therefore making education a candidate for a list of what might be considered the fundamental problems we face.

Potentially we can identify various literatures on or related to the questions of collective intelligence:

1. Biological - "swarm intelligence," social insects

2. Political - epistemic democracy

3. Administrative, public policy - co-creation and co-production of public services, peer production

4. Cognitive - the embodied mind (extended, embedded, enacted), social cognition

5. Technological-AI, machine learning, genetic algorithms, learning analytics, open-source software

6. Evolutionary - "global brain," "noosphere."

While the concept of collective intelligence is prefigured in political philosophy in related notions like "collective consciousness" (Carl Jung), it is in the potential to relate what is being learned in new entomology studies and the most recent developments in information and communication technologies that we see the beginnings of how we might come to understand collective intelligence; the former in what we are learning about the social behavior of insects and the latter in the explanations given to the synergies that connect open source, networked and social media technologies in the Internet as a platform.

Deborah M. Gordon (2015) adds to this initial image of our understanding with her provision of an ecological perspective on the collective behavior in animals. Gordon observes that systems without central control are very com- 
mon in nature; insects and animals providing models of "self-organization" in the way that they socialize in flocks, schools, swarms, etc. While there are useful algorithms that focus on these interactions with respect to the rate or information conveyed, there is as yet no general theory of collective behavior. Furthermore, it is not clear that all collective behavior amounts to collective intelligence. David Sumpter (2010) explains how the study of collective phenomena originates in the application of techniques for understanding systems at different physical scales:

This idea originated from mathematics, theoretical physics, and chemistry. Books by Wiener (1948), Ashby (1947), von Bertalanffy (1968) and Nicolis \& Prigogine (1977) all aimed at providing a framework for the study of collective phenomena. von Bertalanffy argued for the existence of general growth laws of social entities as diverse as manufacturing companies, urbanization, and napoleon's empire. Wiener argued that homeostasis, a stable functioning of natural systems, could be achieved through simple feedback loops. Nicolis and Prigogine aimed to pin down a rigorous theory of nonlinear thermodynamics, explaining similarities between systems at very different scales (pp. 1-2).

Sumpter (2006) uses the theory of complex systems to provide mathematical modeling for understanding forms of collective behavior in the animal kingdom. He formalizes the assumptions made in this study and predicts that behavior occurs such that the individual can be understood to be moving towards collective behavior; something that he claims can be explained both in terms of the individual's "emergence" in the group and through the group's process of "self-organization." "Humans are inherently social animals, whose activities exhibit many of the elements of co-operation and conflict found in other animal societies" (p. 12). Fundamental to understanding these parallels is the centrality of information transfer and sharing (such as information relating to the locating of food sources), in that similar principles would seem to underlie collective decision-making. ${ }^{3}$ In the domain of human behavior, this is probably more easily studied in ironically what must be the most challenging of collective experiences: in, for example, the case of natural disasters where the normal supply of what might be considered the basics are swept away by nature and require a response that can only be collective.

Sumpter (2006) explains how the concept of self-organization of animals can be used to understand the collective behavior of humans by arguing that

the key to understanding collective behaviour lies in identifying the principles of the behavioural algorithms followed by individual animals and of how information flows between the animals. These principles, such as positive feedback, response thresholds and individual integrity, are repeatedly observed in very different animal 
societies. The future of collective behaviour research lies in classifying these principles, establishing the properties they produce at a group level and asking why they have evolved in so many different and distinct natural systems. Ultimately, this research could inform not only our understanding of animal societies, but also the principles by which we organize our own society. http://rstb.royalsocietypublishing.org/content/361/1465/5

In early research done on how organization produces collective decisionmaking, the Marquis de Condorcet (1785) wrote Essai sur l'application de l'analyse à la probabilité des décisions rendues à la pluralité des voix (Essay on the Application of Analysis to the Probability of Majority Decisions) - a document that includes what is known as Condorcet's jury theorem. Condorcet's jury theorem provides the relative probability of a given group of individuals arriving at a correct decision. This theorem has led to studies of the logic of majority judgments (Hawthone, 2009) and to notions of epistemic democracy (List \& Goodin, 2001). In the case of the former, more concern lies with the truth of tracking social decision-making than with the fairness of its effects. However, in both cases it can be said that democratic interests are understood to be present. The approach taken in the article to understand the study of collective intelligence seeks to generalize Condorcet's jury theorem.

Relevant to this interest, Elizabeth Anderson (2007) investigates the epistemic powers of democratic institutions through an assessment of three epistemic models of democracy; one of which is Condorcet's jury theorem. Anderson argues for Dewey's experimentalist model which defines "democracy as the use of social intelligence to solve problems of practical interest (Dewey 1981; Putnam 1990)." As such, Anderson is highlighting that collective intelligence cannot be employed for its own sake and still benefit society as a whole: collective intelligence must deal with the fact that the merit of its interest is itself linked to the problem it addresses. This is what makes the problem a practical problem. However, in saying this, our understating of this point needs to be over to the question of how democracy might better serve diversity.

David Estlund (2008) explains that there is a great deal of variety in epistemic approaches to democracy but that they are all derived from the value of free public discourse that epistemologically guides political practice. $\mathrm{He}$ writes:

One version might say that there are right answers and that democracy is the best way to get at them. Another version might say that there are right answers and there is value in trying collectively to get at them whether or not that is the most reliable way. Yet another: there are no right answers independent of the political 
process, but overall it is best conceived as a collective way of coming to know (and institute) what to do. There are others.

Others philosophers, including Rousseau, Mill, Peirce, Dewey, Habermas, Rawls, and Rorty, have assumed that there is an intimate connection between epistemology and democracy. In particular, it would be useful to briefly focus on Peirce's account of the logic of the "community of inquiry." Forster (2002) argues that "Peirce takes scientific inquiry to be justified not because it is infallible but because it is self-correcting." For Peirce, the idea of truth is that consensus reached in the long run by a community of inquirers (Graupera, 2011). Robert Talisse (2008) has developed an argument for a Peircean conception of democratic politics based on expression of responsible epistemic agency that is only understood to flourish in a democratic society. Returning to Condorcet's jury theorem, the question is, how does a given group of individuals arrive at an idea of truth in a manner that reflects this expression of responsible epistemic agency?

Peer production is regarded as "A Modality of Collective Intelligence" (Benkler et al., 2015) and as a form of "open creation" - a form of collaboration that is exemplified in the interactions between online participants who share and self-organize activities in decentralized ways; ways that are often not dominated by the profit motive. Peer production has come about through the development of distributed and decentralized organizational forms that have not required financial incentives of markets or coercive obligations of bureaucracies (Benkler, 2006, 2013). Collaborative communities on the Internet that operate in this way, include Wikipedia, FLOSS and the GNU/Linux operating system. Peer production is central to the science community and is more readily recognized in the institutionalized systems of peer review and peer governance of academic journal publishing that originated with the Royal Society in the seventeenth century.

In the first instance, peer production can be thought of as social innovation that has arisen as a result of Internet-based networked systems and online platforms. However, our understanding of innovation itself becomes determinant of the relative value of what can be said to be productive and resulting from the interactions of peers.

Innovation and creation is not a function of 'change' but rather of the balancing of change and continuity. Change is a pervasive part of human experience but so is continuity. Successful innovation and creation adapts and improves but also simultaneously preserves and builds on what works. (Murphy, 2015, pp. 66-67)

So it is not "multiplying functions and acquiring new functions" (Murphy, 2015, p. 66) that makes innovation or social innovation, innovative in themselves: this is merely production, elaboration and expansion. Peer production, 
which is also socially innovative, would also need to improve on what already works and furthermore, when the problem demanded, hopefully invent new ways of addressing social needs. The internet as a platform has become the ambit of the cognitive interactions that this form collective action now most rapidly activates.

This said, notions of social and embodied cognition have begun to call into question the unparalleled sway of computer-based models of human cognition that have dominated the science of cognition since the first computers appeared. Increasingly, the abstract, internalist, individualist computerbased model of consciousness and cognition has given way to the model of embodied cognition or what has come to be called the 4 Es; embodied, embedded, extended and enacted. This is a model that has its origins in the work of philosophers like Dewey, Wittgenstein, Heidegger, Merleau-Ponty, Verela and psychologists like Vygotsky and Bruner - the latter two giving special emphasis in social interactions to a kind of pragmatism, culturalism and contextualism. The model of embodied cognition tends to embrace sensorimotor capacities of the body and the body interaction with its physical and cultural environment. This conception overlaps with notions of situated cognition and the extended mind, and includes feedback and species learning as emergent phenomena (Wilson, 2002). There are also strong overlaps between the themes of social cognition and collective intelligence that build on new possibilities of interconnectivity and interaction that have evolved from social media applications. ${ }^{4}$

Assumptions of individualism can be seen in creativity studies that inherit the tradition of Romanticism. In contrast to the individualistic Romantic model of creativity, the "collective design paradigm" is both relational and social. It is more recent and tends to emerge in intersecting literatures of sociology, economics, technology and education surfacing in related ideas of "social capital," "situated learning," and "P2P" accounts of commons-based peer production.

In this model, innovation and creativity are seen as products of social and networked environments - rich semiotic environments in which everything speaks. This collective view of creativity is seen as a product of "systems design" - platforms for collective awareness - that allows a high degree of interaction and rests on principles of distributed knowledge and collective intelligence. The info-communicative turn based on digitalization, speed and compression has realized that all new technologies are significantly languagebased and thus programmable. This in turn has encouraged investment in human capital and the emergence of immaterial labor, leading to the "postmodern flexibilization" of digital labor, facilitated by social networking.

Increasingly these system and platform design issues underlie new epistemologies of design for all distributive knowledge and learning systems in- 
cluding Web 2.0 and semantic web, that stress the importance of intellectual assets and the emergence of global intellectual property rights regimes including patents, copyright, trademarks, advertising, financial and consulting services, and not least education. In this context there is an emphasis on the provision of electronic databases and emergence of new media based on radical concordance of sound, text and image. Digital goods are said to be non-rival, infinitely expansible, discrete, recombinant: they permit radical decentralization but also encourage geographically concentrated clusters and "corridors" based on face-to-face engagement and tacit knowledge. Benkler (2006) talks of the emergence of the paradigm of social or cultural production where increasingly organizational cultures structure cognition and affect, helping to determine knowledge practices and activities.

Yet network systems seem either oligopolistic (e.g., one to many broadcast media) or democratic (e.g., completely horizontal and deterritorialized) based on user-generated cultures. While the literatures on genetic algorithms, learning analytics, open-source software are intimidating in their complexity and rapid growth (Alpaydin, 2004; Mohri et al 2012.), they demonstrate new data-harvest techniques and asymmetrical power relations that disrupt horizontal peer relations at the heart of one version of social innovation.

It is easy to see how new social media have come to represent the development and enhancement of collective intelligence, especially with respect to their capacity to easily store and retrieve information, to encourage the sharing of information and to store data in large databases in the cloud. The Internet platform apps approach exemplifies both online interaction and the distribution of shared knowledge between users that has led some critics to assert the existence of forms of global intelligence such as the notion of the Global Brain built on principles of emergence, encyclopedism, organicism and evolutionary cybernetics. These principles are already implicit in some form in Berners-Lee's World Wide Web and the concept of "social machines."

For instance, Howard Bloom (2001) in Global Brain: The Evolution of Mass Mind from the Big Bang to the 21st Century maintains that our networked culture is both necessary and inevitable. It is essential for our species' survival to harness the power of mass minds that are built on similar principles as natural ecosystems. Less sensationalistic are arguments for the global brain as a self-organizing super-intelligence that unites all forms of human intelligence in the worldwide network of information and communication technologies. The World Wide Web is seen as one manifestation of the global brain hypotheses that rest on dynamic networks that emerge as adaptive complex systems. The Global Brain Institute led by director Francis Heylighen, studies forms of distributed intelligence emerging from the Internet with the aim of building a long term vision of the information society using mathematics and simulations of the Global Brain. ${ }^{5}$ The scientific interests of the 
researchers reveal a structure of related themes: sustainability and resilience of complex systems; mathematical modeling of self-organization; global organizations and dealing with uncertainty; future human metasystem, big history, and media presence; networking, social media and modeling of innovation; self-organization of social systems; system implementation and agent simulation, and the emergence of distributed intelligence.

Tim Berners-Lee (2010), the inventor of the World Wide Web, talks of "social machines" and how we can design social machines that have the capability of helping us to do better science and to improve the working of democracy. He explains how The World Wide Web went live from his physical desktop in Geneva in 1990 demonstrating the profound principle of information sharing and evolving into a ubiquitous tool built on an egalitarian foundation. ${ }^{6}$ In "From the Semantic Web to Social Machines: A Research Challenge for AI on the World Wide Web," Jim Hendler and Tim BernersLee (2009) begin their review by referring to the original vision expressed in 1999 on the nature of social machines on the web where "people do the creative work and the machine does the administration" leading to stage setting for the "evolutionary growth of new social machines" that have the ability to create new forms of social process. They reference the growth of a new generation of Web applications that enhance the democratic structure of user groups, and enhance interactivity and devote themselves to the questions of a new generation of Web technologies that "create tools that allow groups of users to create, share, and evolve a new generation of open and interacting social machines." "They conclude

we look ahead to a time when it will be possible to create and then evolve new kinds of social machines that will provide people, individually and collectively, with the ability to immerse themselves in the accumulated knowledge and the constant interactions of humankind. People's interactions will be not just as passive recipients of information created by others, but also as contributors to this global information space in a way far beyond that of today's Web. In looking to this future, our focus is not primarily in terms of the cyber-infrastructure of high-speed supercomputers and their networked interconnections, but the even more powerful human interactions enabled by these underlying systems (p. 5).

We are only at the beginning of the epoch of digital reason (Peters, 2015) and early in our understanding of processes of digitization that seemingly makes possible these new collective forms of consciousness, awareness, intelligence and action in the user-generated and participatory cultures that are based in peer production and co-creation. ${ }^{8}$ 


\section{Toward a Political Theory of Social Innovation}

Our interest in this paper is the application of collective intelligence and associated forms based on collective awareness engendering collective action that can deliver a political theory and practice of social innovation. We are especially interested in new forms and ways of delivering social goods and services through forms of co-creation and co-production. There are some interesting examples of this kind of thinking that, after the neoliberal era, have led to the discovery of the importance of yoking together innovation and development research in the pursuit of social equality and justice. As Papaioannou (2014) explains

innovation and development researchers now agree that 'making new things in new ways' has positive and negative impact on equality and socio-economic and political relations within and between countries. They recognise that innovation and technical change are significant from the point of view of distributive justice (p. 179).

Papaioannou (2014) makes the argument that innovation and development studies need to enter the territory of normative theory to employ a plausible theory of distributive justice as a basis for economic theories that impinge upon questions of equality and social justice.

Timothy J. Hargrave and Andrew H. Van De Ven (2006) advocate "A Collective Action Model of Institutional Innovation" based on "converging perspectives from the technology innovation management and social movements literature" that conceives institutional change as "a dialectical process in which partisan actors espousing conflicting views confront each other and engage in political behaviors to create and change institutions" (p. 864). Other scholars and designers have also understood the significance of collective intelligence and collective action can be harnessed and focused through platforms that enhance collective awareness. Thus Fabrizio Sestini, Scientific Officer of European Commission's DG CONNECT, a platform for social innovation, remarks:

In just three decades, the internet has evolved from an experimental tool for researchers to a pervasive, omnipresent backbone for society and the economy...

...hyperconnectivity opens up a new field where successful ideas have nothing in common but their unpredictable, bottom-up nature and the ability of exploiting network effects at any level. Trying to understand where the next big game changer can emerge, in 2012 we launched a research initiative called Collective Awareness Platforms for Sustainability and Social Innovation (CAPS). The objective was to explore new solutions at the confluence of social networks, knowledge networks and networks of things. It was a broad 
concept and was very far from the traditional approach to research funding, which normally requires well focussed technological horizons (Arniani et al., 2014, Foreword, p. i).

The European Commission defines these platforms (CAPS) as:

The Collective Awareness Platforms for Sustainability and Social Innovation (CAPS) are ICT systems leveraging the emerging 'network effect' by combining open online social media, distributed knowledge creation and data from real environments ('Internet of Things') in order to create awareness of problems and possible solutions requesting collective efforts, enabling new forms of social innovation (cited in Arniani et al., 2014, p. 9).

Importantly Arniani et al. (2014) document the ways that "the paradigm of 'openness' transforms the way innovation was traditionally conceptualized" (p. 12) as a closed institutional process to one where stakeholders co-create the process of collective awareness, engagement and action thus sharing the knowledge, risks and benefits of the innovation process. In this context, Arniani et al. (2014) discuss various types of social platforms devoted to "engagement" and oriented to Analytics and Visualizations; Collective Assessment; Crowdsourcing; e-Democracy, e-Participation, Direct Democracy; Geo-mapping, Geo-Planning, Geo-Navigation; Motivation \& Engagement; New Economic Models; (Open) Data Integration; Online Deliberation - From Group-Based to Large-Scale; Peer Production and Collaborative Knowledge Creation; Privacy-Aware Tools and Applications; Social Networking \& Social Media Enhancement. ${ }^{9}$

Social innovation increasingly draws on models of "civil intelligence," "distributive social intelligence," new models of emergence and "participatory democracy" that revisit earlier notions of organizational science and learning, and action research models within a technologized framework of the public good that depends on harnessing the full effects of new social movements, collaborative problem solving and Web 2.0 applications. ${ }^{10}$

Clearly, the value of co-creation and innovation is being realized through forms of collective intelligence not only in the public sector but also in commerce and in the third sector, where communities and networks of people use Web 2.0 applications to develop a new paradigm of decentralized citizen engagement on the co-production of social goods and services. Collective intelligence for the public good is the rallying cry for a brave new set of social experiments. It is also useful in the first flush of these developments to realize that there are no guarantees and there are many potential teething problems including understanding the full spectrum of collective intelligence from its awareness and consciousness to models of collective action. Greater attention needs to be paid to the process of collective ideation and learning. 
Characteristically in our communities there is no one cultural- or world-view, and there are many competing narratives that frame and structure social problems. At the moment, Web 2.0 applications are well suited to sharing information and harnessing the power of user-generated groups but have less success in structuring discourse in online deliberation as a rational process.

The need to pay greater attention to the process of collective ideation and learning eludes to the distinctive status that student's hold in the community of grassroots actors that the European Commission (2014), in its development of CAPS platforms, seeks to engage. Social entrepreneurs, hackers, civil society organizations operate in or engage with the private sector where political economy functions according to a distinctive set of objectives. While students will be drawn to sharing knowledge, risks and the benefits of the innovation process, their relationship with the institution is determinant in the scope that this ideation is permitted to take. Any political theory that seek to acknowledge the inclusion of students in such a project as that promoted by the European Commission will need to grapple with the fact that students have paradoxically accepted to form themselves as workers in an environment where the benefits of intellectual property are governed by the institution. Co-production through networked engagement on platforms that facilitate interdisciplinary ideation would require a transformation of the way power is administered in the university for students to be actors in social innovation. To take a truly "bottom-up, open and distributed approaches" that would exploit the existing network effects that are constantly emerging in student learning and research supposes a break with the present institutional model and the vitalization of learning institutions.

\section{NOTES}

1. The symposium discussed "issues such as the challenges of open innovation in the public sector, the differences between co-creation (open innovation) and coproduction (open services), the different types of co-creation, the characteristics of co-production initiatives, the factors that influence co-production and co-creation with citizens, the incentives that citizens have to be involved in co-production, the role of open data and social media in co-producing public services" at http://faculty. washington.edu/jscholl/hicss $48 /$ symposium.html

2. "Co-creation Is Key to Innovation in Government," at http://mind-lab.dk/wpcontent/uploads/2014/09/Understanding_Society_Winter_2010_CBason.pdf

3. See Sumpter's website at http://www.collective-behavior.com/Site/Home.html

4. See Social Cognition and Collective Intelligence, http://video.mit.edu/watch/ social-cognition-and-collective-intelligence-7792/ featuring the work of Thomas Malone, Director of the MIT Center for Collective Intelligence at the Sloan School of Management. 
5. See the Global Brain Institute at https://sites.google.com/site/gbialternative1/ and Heylighen's personal webpage at http://pespmc1.vub.ac.be/HEYL.html

6. See http://www.scientificamerican.com/article/long-live-the-web/. See also https://www.youtube.com/watch?v=X8_FKma2H7k

7. See http://web.stanford.edu/class/cs227/Readings/hendler-berners-lee-semanticweb.pdf

8. See http://p2pfoundation.net/Co-Creation.

9. See also the list of "Existing Tools and Communities that the CAPS Projects Build from and Collaborate with" that are mostly web applications, pp. 39-44, at http://booksprints-for-ict-research.eu/wp-content/uploads/2014/07/BS5-CAPS-FIN003.pdf

10. See e.g., http://en.wikipedia.org/wiki/Civic_intelligence and Schuler (2007).

\section{REFERENCES}

Alpaydin, E. (2004), Introduction to Machine Learning. Cambridge, MA: MIT Press. Anderson, E. (2006), "The Epistemology of Democracy," Episteme: A Journal of Social Epistemology 3(1/2): 8-22, at https://muse.jhu.edu/journals/episteme/v 003/3.1 anderson.html

Arniani, M., Badii, A., De Liddo, A., Georgi, S., Passani, A., Piccolo, L.S.G., and Teli, M. (2014), Collective Awareness Platform for Sustainability and Social Innovation: An Introduction. www.caps2020.eu/library

Benkler, Y. (2006), The Wealth of Networks: How Social Production Transforms Markets and Freedom. New Haven, CT: Yale University Press.

Benkler, Y. (2013), "Peer Production and Cooperation," in J. M. Bauer and M. Latzer (eds.), Handbook on the Economics of the Internet. Cheltenham: Edward Elgar.

Benkler, Y., Shaw, A., and Hill, M. (2015), "Peer Production: A Form of Collective Intelligence," at http://mako.cc/academic/benkler_shaw_hill-peer_production_ci.pdf Berners-Lee, Tim (2010), "Long Live the Web," Scientific American, at http:// www.cs.virginia.edu/ robins/Long_Live_the_Web.pdf

Bloom, Howard K. (2000), The Global Brain: The Evolution of Mass Mind from the Big Bang to the 21st Century. New York, NY: Wiley.

Dewey, John (1981), "Creative Democracy: The Task before Us," in J. A. Boydston (ed.), The Later Works of John Dewey, 1925-1953, vol. 14, Essays. Carbondale, IL: Southern Illinois University Press, 224-230.

Estlund, D. (2008), "Introduction: Epistemic Approaches to Democracy," Episteme: A Journal of Social Epistemology 5(1): 1-4.

European Commission (2014), Collective Awareness Platforms for Sustainability and Social Innovation: An Introduction, at http://booksprints-for-ict-research.eu/wpcontent/uploads/2014/07/BS5-CAPS-FIN-003.pdf

Forster, Paul (2002), "Scientific Inquiry as a Self-correcting Process," CoMmens, Digital Companion to C. S. Peirce, at http://www.commens.org/encyclopedia/ article/forster-paul-scientific-inquiry-self-correcting-process-0

Gordon, Deborah M. (2015), "Collective Behavior in Animals: An Ecological Perspective," https://docs.google.com/file/d/0B4-bDrtyS31XUGxmem9Fc0w2SFE/edit, The Collective Intelligence Handbook [tentative title], Thomas W. Malone and 
Michael S. Bernstein (eds.). Cambridge, MA: MIT Press, at http://cci.mit.edu/ CIchapterlinks.html

Graupera, J. (2011), "Dependences between Logic and Community: Philosophical Implications of Peirce's Categories for Praxis," Ramon Llull Journal of Applied Ethics 1(2): 179-194.

Hawthone, J. (nd), "Voting in Search of the Public Good: The Probabilistic Logic of Majority Judgments," http://faculty-staff.ou.edu/H/James.A.Hawthorne-1/Hawthorne--Jury-Theorems.pdf

Hendler, Jim, and Tim Berners-Lee (2009), "From the Semantic Web to Social Machines: A Research Challenge for AI on the World Wide Web," Artificial Intelligence 174(2): 156-161, at http://www.sciencedirect.com/science/article/pii /S0004370209001404

Jung, Carl (nd), "The Concept of Collective Unconscious," at http://www.bahai studies.net/asma/The-Concept-of-the-Collective-Unconscious.pdf

Komninos, N. (2008), Intelligent Cities and Globalisation of Innovation Networks. New York: Routledge.

List, C., and Goodin, R. E. (2001), "Epistemic Democracy: Generalizing the Condorcet Jury Theorem," The Journal of Political Philosophy 9(3): 277-306. At http://eprints.lse.ac.uk/705/1/listgoodin.pdf

Magno, F., and Cassia, F. (2014), “Public Administrators' Engagement in Services Co-creation: Factors that Foster and Hinder Organisational Learning about Citizens," Total Quality Management \& Business Excellence, DOI: 10.1080/147833 63.2014.918706, http://dx.doi.org/10.1080/14783363.2014.918706

Mohri, M. Afshin Rostamizadeh, and Ameet Talwalkar (2012), Foundations of Machine Learning. Cambridge, MA: MIT Press.

Mulgan, Jeff (2014), "True Collective Intelligence? A Sketch of a Possible New Field," Philosophy \& Technology 27(1): 133-142.

Murphy, P. (2015), Universities and Innovation Economies: The Creative Wasteland of Post-industrial Society. Farnham: Ashgate.

Nambisan, S., and Nambisan, P. (2013), "Engaging Citizens in Co-Creation in Public Services: Lessons Learned and Best Practices.” Research Report, IBM Center for the Business of Government. Collaboration across Boundaries Series.

Papaioannou, T. (2014), "Innovation and Development in Search of a Political Theory of Justice," International Journal of Technology and Globalisation 7(3): 179-202.

Pestoff, V. (2012), "Co-production and the Third Sector Social Services in Europe: Some Concepts and Evidence," Voluntas 23: 1102-1118.

Peters, M.A. (2015), "The University in the Epoch of Digital Reason Fast Knowledge in the Circuits of Cybernetic Capitalism," in Paul Gibbs, Oili-Helena Ylijoki, Carolina Guzmán-Valenzuela, and Ronald Barnett (eds.), Universities in the Time of Flux: An Exploration of Time and Temporality in University Life. London: Routledge, 9-31.

Peters, M.A., and Reveley, J. (2015), "Noosphere Rising: Internet-based Collective Intelligence, Creative Labour, and Social Production," Thesis Eleven, DOI: $10.1177 / 0725513615575932$ 
Phills, J. (2009), "Rediscovering Social Innovation," Stanford Social Innovation Review, at http://www.ssireview.org/articles/entry/rediscovering_social_innovation/

Putnam, H. (1990), “A Reconsideration of Deweyan Democracy,” Southern California Law Review 63: 1671-1697.

Schuler, Douglas (2007), "Civic Intelligence and the Public Sphere," in Mark Tovey (ed.), Collective Intelligence: Creating a Prosperous World at Peace. Oakton, VA: Earth Intelligence Network.

Sumpter, David (2010), Collective Animal Behavior. Princeton, NJ: Princeton University Press.

Talisse, Robert (2008), A Pragmatist Philosophy of Democracy. New York: Routledge.

Malone, Thomas W., and Michael S. Bernstein (eds.), The Collective Intelligence Handbook [tentative title]. Cambridge, MA: MIT Press, http://cci.mit.edu/CI chapterlinks.html

Vorrberg W. H., V. J. J. M. Bekkers, and L. G. Tummers (2014), “A Systematic Review of Co-Creation and Co-Production: Embarking on the Social Innovation Journey," Public Management Review, DOI: 10.1080/14719037.2014.930505, http://dx.doi.org/10.1080/14719037.2014.930505

Wilson, Timothy (2002), Strangers to Ourselves: Discovering the Adaptive Unconscious. Cambridge, MA: Harvard University Press. 